Voix et Images

voixetimages

\title{
Amours, délices et orgues
}

\section{Lucie Robert}

Volume 13, numéro 2 (38), hiver 1988

Le propre du corps Roger Des Roches

URI : https://id.erudit.org/iderudit/200721ar

DOI : https://doi.org/10.7202/200721ar

Aller au sommaire du numéro

\section{Éditeur(s)}

Université du Québec à Montréal

\section{ISSN}

0318-9201 (imprimé)

1705-933X (numérique)

Découvrir la revue

Citer cet article

Robert, L. (1988). Amours, délices et orgues. Voix et Images, 13(2), 357-359.

https://doi.org/10.7202/200721ar d'utilisation que vous pouvez consulter en ligne.

https://apropos.erudit.org/fr/usagers/politique-dutilisation/ 


\section{Dramaturgie}

\section{Amours, délices et orgues}

\section{par Lucie Robert, Université du Québec à Montréal}

À l'occasion de la parution de la nouvelle pièce de Gratien Gélinas, les éditions Leméac rééditent, dans la collection «Thêatre», les deux classiques que sont devenus Tit-Coq et Bousille et les Justes 1 . Fidèle à lui-même, Gratien Gélinas aura ainsi confirmé la régularité de ses publications qui paraissent au rythme moyen, lent mais soutenu, d'un texte tous les dix ans: TitCoq en 1948, Bousille et les Justes en 1959, Hier les enfants dansaient en 1966, les Fridolinades en 1980 et maintenant, en 1987, la Passion de Narcisse Mondoux ${ }^{2}$. Chaque nouveau texte, attendu avec une sorte d'impatience, a donné lieu à une relecture de l'ensemble de cette œuvre où, chaque fois, l'on a regretté de ne pas retrouver la magie des origines qui fit la fortune de Fridolin, de Tit-Coq et, dans une moindre mesure, celle de Bousille, personnages désormais incontournables de notre dramaturgie. Car on ne peut pas dire que la famille Gravel, de Hier les enfants dansaient, ait laissé de bien grands souvenirs dans la mémoire théâtrale du Québec. L'œuvre de Gratien Gélinas n'a en effet rien gagné à son embourgeoisement dans une écriture dont le style imite celui de Marcel Dubé avec malheureusement assez peu de bonheur. L'art de Gélinas repose plus sur la théâtralité que sur l'écriture du texte, plus sur le personnage que sur la situation.

La Passion de Narcisse Mondoux reprend ainsi le principe sur lequel Gratien Gélinas avait construit son œuvre à ses débuts et qui lui a réussi. Pièce écrite par un comédien pour lui-même, elle est d'abord la création d'un personnage - et même de deux, si l'on songe au personnage de Laurencienne Robichaud, écrit pour Huguette Oligny - , avant d'être une intrigue, une histoire, une vision ou un projet.

Parvenu à l'âge respectable de soixante-cinq ans, Narcisse Mondoux, maître plombier à la retraite, ne doit rien à personne et il entend bien soigner ses vieux os avant de mourir. Veuve depuis la première scène, qui la montre au salon funéraire, Laurencienne Robichaud entend pour sa part réaliser son plus vieux rêve, devenir mairesse de Saint-Esprit-en-Bas. S'ensuit évidemment un quiproquo où Narcisse, qui n'a d'ailleurs aucun intérêt pour la vie publique, dépose son bulletin de candidature à la mairie dans le seul but de séduire sa douce. Il y a 
méprise, Laurencienne convoitant cette mairie pour elle-même et non pour son futur mari. On voit alors se poursuivre un dialogue où s'affrontent une Laurencienne libérée des conventions maritales et un Narcisse qui tente de se situer dans un monde féminin d'un ordre nouveau qu'il connaît mal et dont il ne partage pas tous les projets. Les dialogues sont gentils, jamais tristes ni violents. Le duel est plus drôle que dangereux: seul Narcisse ignore tout de la situation réelle dans laquelle il se débat sous l'œil amusé de Laurencienne et sans doute du public.

Dans cette petite histoire d'amour sans autre prétention que de mettre en valeur le talent des interprètes, on ne trouvera pas de moralisme étroit, pas de conflit entre le devoir et la famille, pas de victime consentante. Bluette sympathique sur les amours du troisième âge, la Passion de Narcisse Mondoux ne sera pas une grande pièce de notre dramaturgie, mais peut-on en vouloir à Tit-Coq et à Marie-Ange d'avoir enfin trouvé la paix?

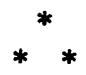

Sur un tout autre registre, paraît également le premier texte dramatique de Madeleine Ouellette-Michalska. Écrit pour la radio et diffusé en version abrégée par Radio-Canada le 29 octobre 1986, dans une réalisation de Jean-Guy Pilon, la Danse de l'amante ${ }^{3}$ a pour origine, non pas le personnage, mais l'acte d'écrire et la problématique générale qu'il sous-tend. L'acte d'écrire ici s'inscrit, comme souvent dans l'œuvre de l'auteure, au cœur d'une relation amoureuse fondée, dans la tradition française de l'écriture au féminin sur le corps et l'ensemble des pulsions qui l'habitent. Dialogues, au pluriel, entre l'homme et l'amante, entre la fille et la mère, entre le fils et la mère, le texte ne crée pas de personnage ni d'action à proprement parler. Il exprime le rapport amoureux, rapport conflictuel dont la source remonte à la scène inaugurale que les deux protagonistes doivent retrouver pour enfin la dépasser dans un rapport harmonieux et consentant. Ainsi le texte nous entraîne-t-il dans une réflexion sur les relations à la mère, réflexion portée par une série de variations sur le temps et sur l'espace qui séparent les amants et qui, ultimement, les rapprocheront. Une fois cette distance franchie, le langage trouve une fonction nouvelle, plus créatrice. Comme plusieurs autres textes de Madeleine Ouellette-Michalska, la Danse de l'amante ne concède rien à la facilité du réalisme, ce que lui permet encore mieux le médium choisi pour sa diffusion. La difficulté apparente du texte, qui doit en fait se lire comme un poème à plusieurs voix, ne devrait pas masquer l'intérêt de cette vision de la mère, vision ambivalente que l'auteure refuse de céder aux fantasmes habituels.

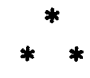

Parmi les jeunes auteurs à succès, Michel Marc Bouchard occupe une place à part, tant il produit l'effet d'une comète. Quoiqu'il écrive depuis une dizaine d'années, ses pièces n'ont connu l'édition que très récemment. Depuis trois ou 
quatre ans en effet, Michel Marc Bouchard est en train de devenir un des auteurs les plus souvent édités de sa génération. Certaines de ses pièces sont plus diffusées par le livre que par la scène. Certaines, créées il y a quelque temps déjà, connaissent un regain de vie.

Rock pour un faux-bourdon 4 est un bel exemple. Créée par le Thêâtre de la Vieille 17 et le Centre national des arts d'Ottawa, en février 1983, dans une mise en scène de Pierre Collin, la pièce a été reprise au Théâtre d'été Mic Mac de Roberval en juin 1985, dans une mise en scène de l'auteur. À l'occasion de cette nouvelle production, l'auteur ajoute à son texte un nouveau personnage, celui de l'agent Boudreault. Puis la pièce est jouée en 1986 par les finissants et les finissantes de l'Option-théâtre du cégep Lionel-Groulx, dans une mise en scène de Claude Poissant, et reprise, en janvier 1987, à la salle Fred-Barry, à Montréal. À l'occasion de cette troisième production, monsieur Boudreault devient madame Boudreault et, pourquoi pas, on ajoute encore un personnage, celui de Judith.

C'est cette troisième version que publie Leméac, une version augmentée si l'on peut dire, mais aussi rajeunie, mise au goût du jour. Sous-titrée «drame musical», elle prend parfois en effet l'allure d'un vidéoclip, effet que renforcent précisément les deux personnages ajoutés et que créent surtout l'âge des personnages, la dureté apparente des premières scènes, le rythme et l'agencement des plans et le «happy ending» qui n'a rien retenu des conventions réalistes et des normes actuelles du vraisemblable.

1 Gratien Gélinas, Tit-Coq, préface de Marcel Dubé, postface de Laurent Mailhot, Montréal, Leméac, 1987, 173 p. Photos. («Théâtre», n 163). Bousille et les justes, suivi d'«Extraits de critique», Montréal, Leméac, 1987, 180 p. Photos. («Théâtre», n 164).

2 Gratien Gélinas, la Passion de Narcísse Mondoux, Montréal, Leméac, 1987, 135 p. Photos. («Théâtre», n 162).

3 Madeleine Ouellette-Michalska, la Danse de l'amante, postface de Chantal Chawaf, Montréal, la Pleine Lune, 1987, 64 p.

4 Michel Marc Bouchard, Rock pour un faux-bourdon, préface de Claude Poissant, Montréal, Leméac, 1987, 127 p. Photos. («Théâtre», $n^{\circ} 165$ ). 